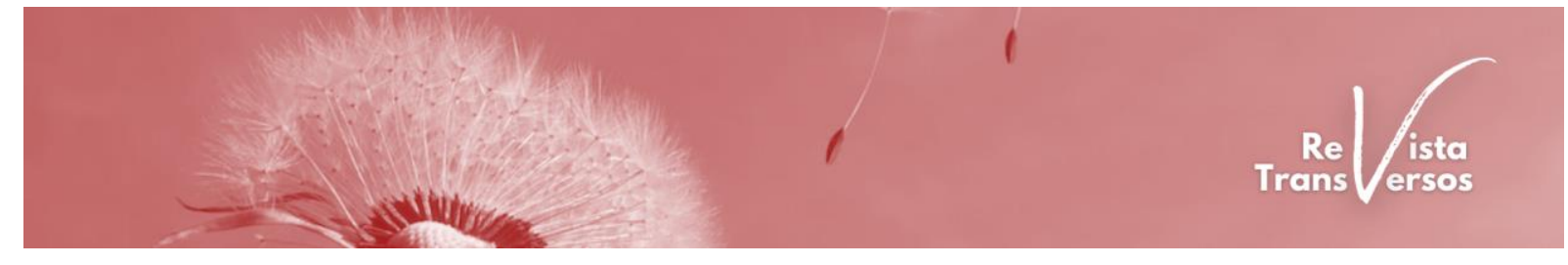

DOI: $10.12957 /$ transversos.2021.59121

\title{
FIGURAÇÕES FEMININAS SUBVERTIDAS NO CONTO SURVIVAL SHIP(1951) DE JUDITH MERRIL: FICÇÃO CIENTÍFICA E GÊNERO EM NEGOCIAÇÃO
}

\section{SUBVERTED FEMALE FIGURES IN JUDITH MERRIL'S SURVIVAL SHIP (1951): SCIENCE FICTION AND GENDER IN NEGOTIATION}

\author{
Janis Caroline Boiko da Rosa \\ Universidade Federal do Paraná \\ janisboikor@gmail.com
}

\section{Resumo:}

Survival Ship (1951), texto de Judith Merril, narra a história do lançamento de uma espaçonave colonizadora comandada por mulheres. O conto foi publicado em um momento de virada conservadora, em que o papel da mulher na casa era continuamente enfatizado. Desse modo, a contradição entre a publicação e o discurso oficial nos leva a questionar como a autora manejou tais figurações. Assim, este trabalho busca entender como a autora subverte narrativas e figuras típicas dos discursos oficiais para criar um conto que desafia padrões de representação de gênero. Para tanto, partiremos de uma concepção de gênero e da ficção científica como códigos linguísticos e pensaremos a subversão como uma forma de inversão de significado e transgressão de narrativas culturalmente disponíveis.

Palavra-Chaves: Ficção científica; Figuração feminina; Judith Merril; Subversão.

\begin{abstract}
Survival Ship (1951), a text by Judith Merril, tells the story of the launch of a colonizing spacecraft commanded by women. The story was published in a moment of conservative overturn, in which the role of women at home was continually emphasized. Therefore, the contradictions between the publication and the official discourse leads us to question how the author handled such figurations. Thus, this work seeks to understand how Judith Merril subverted narratives and figures typical of official speeches to create a short story that defies gender representation patterns. In order to do so, we will begin by discussing gender and science fiction as linguistic codes as well as interpret subversion as a form of inversion of meaning and transgression of culturally available narratives.
\end{abstract}

Keywords: Science fiction; Female figures; Judith Merril; Subversion. 


\section{Survival Ship no diálogo entre gênero e ficção científica}

Survival Ship foi um conto publicado por Judith Merril na revista Worlds Beyond ${ }^{1}$ em janeiro de 1951. Judith Merril atuou no campo da ficção científica entre 1948 e 1997 e, em seu trabalho criativo, a escritora se apropriou do gênero textual para abordar questões políticas diversas, compreendendo a ficção científica (SF) como um dos únicos meios pelos quais poderia analisar criticamente o conservadorismo de sua época e compreendendo-a como uma forma de produção textual que parte da premissa de que o mundo como o conhecemos pode ser diferente (LAMONT; NEWELL, 2012). Em Survival Ship a autora explorou a sexualidade e os papéis sexuais (e, por consequência, de gênero) no espaço por meio da história da decolagem da nave Survival, com uma missão exploradora e colonizadora. O lançamento da nave, tendo como destino a constelação de Sírius, é pesadamente coberto pela imprensa, que discute suas características e o milagre tecnológico que representa, mas não consegue revelar a identidade da tripulação. A curiosidade com relação às identidades em segredo conduz o leitor por uma série de pequenas pistas, culminando com a revelação das relações de gênero heterodoxas, assim como com a inversão de expectativas tangentes às figurações tradicionais de personagens femininas e masculinas nas narrativas de ficção científica e na mídia de massa da época.

Por sua habilidade em reverter expectativas e pela figuração de mulheres em novos papéis, compreendemos a narrativa de Merril como subversiva, no sentido de um texto que inverte representações tradicionalistas e perturba concepções e narrativas vigentes acerca do papel da mulher. Esse tipo de subversão foi realizado por diversas escritoras de ficção científica, que se apropriaram dos tropos narrativos do gênero textual para questionar relações de gênero de seu período de escrita. Esses questionamentos e críticas foram inseridos no subtexto de publicações através de diferentes estratégias em diferentes períodos. Em 1950, mulheres escreviam a partir do chamado subúrbio galáctico, ou seja, de uma visão e interpretação de feminilidade doméstica. Partindo do lar, escritoras conseguiram tratar de preocupações femininas e feministas, abordando o medo da bomba atômica, questões raciais, a demanda de consumismo que pesava sobre as mulheres, as dificuldades de atuação no mercado de trabalho e a sua exclusão de cargos de responsabilidade.

\footnotetext{
${ }^{1}$ Revista digest (mais curta que o tamanho padrão) de ficção científica e fantasia publicada nos anos de 1950 e 1951, editada por Damon Knight.
}

Revista Transversos. Rio de Janeiro, n. 23, dez. 2021. 
Neste sentido, ao analisarmos o texto nos cabe questionar: de que maneira Judith Merril figura relações de gênero no conto? Qual o papel da mulher na viagem espacial? Como a autora transgride imagens tradicionais da mulher? Quais os limites da subversão das figurações? Onde, no texto, a autora cede? Como ela justifica suas representações? Como essas figurações são subversivas? O que seria a subversão das figurações de gênero na ficção científica de 1950? A que concepções do papel da mulher o texto se refere e contra o que se rebela? A fim de trabalharmos esta discussão se faz necessário apresentar um breve mapeamento das representações midiáticas das mulheres e das expectativas impostas sobre estas, além de pensar em como este cenário se relaciona com a ficção científica, como autoras publicavam e como mulheres eram apresentadas nas revistas de SF do período.

\section{Gênero na cultura de Guerra Fria}

Ao fim da 2a Guerra Mundial, os Estados Unidos passaram por uma onda de crescimento econômico. As taxas de empregabilidade mais altas, a abundância de bens materiais e a tecnologização do lar se deram concomitantemente a uma virada conservadora em resposta a uma nova posição na política internacional. Emergiu, então, uma nova autoimagem do país, informada por um desejo de domesticidade, na qual a mulher retornaria a casa (equipada com significantes de abundância material) para cuidar da família e filhos após seus anos atuando no mercado de trabalho durante a guerra. Essa imagem também foi influenciada pelo advento das armas nucleares, cujo imenso poder destrutivo impactou o imaginário nacional com um sentimento de paranoia e necessidade de diferenciação de si com relação ao inimigo soviético. $\mathrm{Na}$ ficção científica pulp ${ }^{2}$, essas imagens se apresentaram no foco dado ao lar e no pessimismo com que a ciência era vista (MARTIN, 2014).

No pós-Segunda Guerra Mundial, mulheres foram abordadas por discursos políticos que lhes pediam para abandonar seus empregos e focar suas energias na casa, deixando suas vagas para os veteranos. A atividade doméstica e o cuidado familiar eram associados ao dever cívico em discursos políticos dirigidos ao público feminino. Contudo, essas colocações não foram cumpridas ao pé da letra, muitas mulheres trabalhavam e algumas continuavam a trabalhar

\footnotetext{
${ }^{2} \mathrm{O}$ termo pulp se refere a revistas feitas de papel barato, conhecidas como entretenimento rápido e sem grandes pretensões artísticas.
} 
mesmo depois de casadas e com filhos (LEFAUCHEUR, 1991). O que Betty Friedan (1971) observou neste sentido, é que, ainda que um terço das mulheres atuasse no mercado de trabalho, poucas seguiam carreira, geralmente essas mulheres eram casadas, trabalhavam como secretárias ou vendedoras em empregos de meio expediente e com um objetivo financeiro específico, como pagar estudos do marido ou dos filhos.

Nas revistas, a mulher emergiu bela, frívola, jovem e fofa - quase infantil. Passiva, essa mulher se satisfazia com um universo composto de quarto, cozinha, bebês e sexo. A atividade sexual era, de acordo com Betty Friedan (1971), a única paixão e objetivo permitido para mulheres que deveriam buscar um homem. Para a maioria dos editores, as mulheres não tinham interesse em grandes assuntos públicos, em negócios nacionais ou internacionais, mas apenas em temas voltados à família e ao lar. A única política que poderia interessar às leitoras seria aquela que impactaria diretamente a vida doméstica e o mesmo desinteresse se daria com relação a assuntos sociais, científicos, artísticos e políticos. Friedan notou que essas convicções se tornaram uma profecia autorrealizada: aos anos 1960 a percentagem de mulheres interessadas em política era baixíssima (FRIEDAN, 1971; YASZEK, 2008).

Betty Friedan (1971) observou que essa imagem feminina foi concebida por escritores do sexo masculino. Com o retorno dos veteranos da $2^{\text {a }}$ Guerra Mundial, as mulheres que trabalhavam nas revistas começaram a abandonar o campo e a ter filhos, sendo substituídas por homens marcados pela guerra, que sonhavam com filhos e uma vida doméstica tranquila. Elaine Showalter (2009) observou que tanto na ciência da época quanto na cultura popular ocorreu um esforço para tornar a domesticidade mais palatável para mulheres. Discursos afirmando os prazeres de cozinhar, cuidar da casa e criar filhos eram divulgados ao mesmo tempo em que mulheres que queriam manter seus salários e independência eram ameaçadas com diagnósticos de neurose e acusadas de prejudicar suas famílias. Era responsabilidade das mulheres criar filhos que seriam cidadãos bem ajustados e úteis, de modo que permitir que mães trabalhassem seria prejudicial para as crianças e para o país como um todo.

Ainda que discursos oficiais, científicos e midiáticos investissem na figuração de mulheres ambiciosas como destrutivas e danificadas, estas figuras concorriam com a imagem da mulher fora do lar, a qual resistia à dissolução. Segundo Lisa Yaszek (2008), autora que dialogou os trabalhos de 1963 de Betty Friedan com pesquisas mais atuais, editores e escritores afirmavam tanto a narrativa do ideal doméstico quanto as antigas expectativas de realização profissional para 
mulheres. Mais especificamente, enquanto revistas femininas celebravam feminilidade e maternidade, estas também reconheciam que as mulheres viveram fora do lar.

Para Lisa Yaszek (2008), as escritoras de ficção científica da década de 1950 desafiaram a mística feminina, imaginando como mulheres poderiam se envolver em novos modos de formação de lares e criação de crianças. As narrativas sobre a alienígena-outra eram particularmente interessantes como possibilidades de experimentação. É claro que a ficção científica não era um espaço totalmente livre de representações femininas reacionárias, autores como Philip José Farmer e Paul W. Fairman ${ }^{3}$ reafirmaram narrativas conservadoras de dever patriótico feminino ao contar histórias de mulheres aparentemente independentes que acabavam por estar mais confortáveis consigo mesmas quando a serviço de outros. Mesmo narrativas de alienígenas passavam por processos parecidos, criaturas ameaçadoras poderiam ser docilizadas e convertidas em esposas dedicadas - e seriam ainda mais felizes após a conversão, atingindo seu verdadeiro destino biológico intergaláctico.

Algumas características eram comuns à escrita feminina, dentre elas a extrapolação do futuro partindo dos arranjos tecnológicos e científicos do pós-guerra estadunidense e a apropriação de formatos narrativos como a space opera e o holocausto nuclear, e de tropos como o cientista herói e o alienígena-outro. Contudo, a característica que diferenciava a escrita feminina era o foco no impacto da ciência e da tecnologia sobre as mulheres e suas famílias. Essa perspectiva era frequentemente narrada do ponto de vista de mulheres que se definiam primeiramente, mas não exclusivamente, como mães, viúvas e companheiras (YASZEK, 2008). As reações a esses textos eram mistas e por vezes contraditórias: por um lado haviam fãs, editores e escritores condenavam os trabalhos de autoria feminina, os chamando de narrativas de “corações pulsantes e fraldas" produzidas por um bando ou gansaral ${ }^{4}$ de donas de casa, vindas para estragar o gênero para "todo mundo" (LARBALESTIER, 2002 apud YASZEK, 2008: p.23), por outro, havia membros da comunidade dispostos a aceitar esses trabalhos, publicá-los e a premiá-los.

\section{Feminilidade em figurações: gênero como código}

\footnotetext{
${ }^{3}$ Ambos escritores americanos de ficção científica e fantasia. Paul W. Fairman foi também editor das revistas Amazing Stories, If e Fantastic.

${ }^{4}$ Coletivo de gansos, remetendo aos barulhos desagradáveis que incomodavam o fandom.
} 
Em 2002, Brian Attebery publicou o livro Decoding Gender in Science Fiction, no qual propôs que interpretássemos tanto gênero quanto a fiç̧ão científica como sistemas de sinais. $\mathrm{O}$ autor sugeriu que pensássemos gênero como modo de assinalar significados sociais e psicológicos a diferenças sexuais percebidas e a ficção científica como um sistema de geração e interpretação de narrativas. Ambos os códigos se sobrepõem e dependem da linguagem, que seria uma espécie de código mestre, pelo qual os outros sistemas culturais seriam transmitidos, verificados e analisados. Ainda, pensar em códigos implica pensar em quem foi educado dentro do código e está capacitado a compreender a mensagem e quem é excluído deste grupo, para quem o código é incompreensível, definindo fronteiras de "nós" e "eles". Tanto gênero quanto ficção científica possuem vocabulários, símbolos ou narrativas particulares que ocupam a função de demarcar a fronteira entre aqueles que conhecem o código e aqueles que desconhecem: o uso de brincos em certos lugares e em certos corpos, no caso de gênero, ou as abreviações imprecisas (como uso de sci-fi em vez de SF), no caso da ficção científica, podem rotular um outsider ou significar uma mensagem de dissidência.

Attebery (2002) observa ainda que o gênero, como código, é muito mais penetrante que a ficção científica. $\mathrm{O}$ indivíduo já nasce inserido em um código de gênero e o aprende desde o nascimento, de modo que suas regras passam a fazer parte da própria estrutura da consciência do sujeito (que também se apropria e remolda essas normas de maneiras múltiplas). Attebery nota que, assim como na linguagem, onde os fonemas precisam diferir uns dos outros, um gênero só é significativo na medida em que se difere de outro. Gênero usualmente é concebido num padrão binário mutuamente exclusivo, ou com características mutuamente exclusivas.

Acerca da relação do código com os indivíduos, Attebery (2002) nota que performamos os significantes "homem”, "marido”, "pai", "filho", "filha”, "mãe”, "mulher” e etc. de acordo com nossos dialetos pessoais e regionais ${ }^{5}$. Muito do que temos em comum com outros membros do nosso gênero é o grau no qual diferimos das definições culturais do gênero oposto. Sinais nãoverbais de gênero dispostos sobre corpos podem ser roupas, produtos químicos para mascarar ou realçar odores corporais, penteados, cosméticos, postura, gestos, tom de voz e inflexão, padrões

\footnotetext{
${ }^{5}$ Para Judith Butler (2003: p.200-201) a identidade de gênero mesma é baseada na performance repetida e estilizada de certos atos ao longo do tempo. $O$ efeito do gênero, diz a autora, se produz pela estilização do corpo e deve ser entendido como forma corriqueira pela qual gestos, movimentos e comportamentos constituem a ilusão de um eu permanentemente marcado pelo gênero.
} 
de contato visual, etc. Dentro destes códigos o corpo mesmo se torna símbolo e seu significado pode mudar segundo a apresentação e o contexto.

Joan Scott (1990) enfatiza que no interior dos processos e estruturas de gênero deve haver espaço para a agência humana, concebida como tentativa (ao menos parcialmente racional) de construir uma identidade, um conjunto de relações pessoais e uma sociedade dentro de certos limites e dotada de uma linguagem, que contenha a possibilidade de resistência e reinterpretação. Pensando uma definição de gênero que respeite essa demanda e conceba poder como micropoderes espalhados nas relações e interações sociais, a autora expôs uma definição contendo duas partes e diversos subconjuntos interrelacionados. $\mathrm{O}$ núcleo da definição apresentada por Scott repousa na conexão entre duas proposições: o gênero é um elemento constitutivo de relações sociais baseadas em diferenças notadas entre sexos e é também uma forma de dar significado a relações de poder. Neste sentido, mudanças nas relações sociais correspondem a mudanças nas representações de poder e as negociações de figuras são, também, relações de imposição de poder e resistência.

Como elemento constitutivo das relações sociais baseadas em diferenças sexuais, o gênero implica quatro elementos: símbolos culturalmente disponíveis que evocam representações (como Eva e Maria, a femme fatale etc.); conceitos normativos que pronunciam a interpretação dos significados dos símbolos, limitando suas possibilidades metafóricas e afirmando os significados de feminino e masculino, expressos em doutrinas religiosas, educativas, políticas, científicas ou jurídicas (um método de leitura dos códigos); o terceiro aspecto é referente a instituições e estruturas sociais constitutivas de gênero, relações de parentesco, relações de e com o mercado de trabalho, formas da educação, o sistema político excludente; o quarto elemento é ligado a gênero e a subjetivação, explicando que durante a infância os indivíduos passam por um processo de culturação que os generificam - as identidades generificadas são diferentes em diferentes épocas e sociedades, tendo relação com organizações sociais e figurações. Nenhum desses elementos pode operar sem os outros (SCOTT, 1990).

Ao compreendermos gênero como forma de dar significado a relações de poder e a relações baseadas em diferenças sexuais, bem como algo que se utiliza de um conjunto de figurações simbólicas e que possui uma chave interpretativa para estes símbolos, não só podemos dialogar a definição de Scott com a proposta de Attebery para pensarmos as intersecções entre códigos de gênero e de ficção científica, mas também podemos pensar em maneiras pelas quais 
sentidos são invertidos e narrativas padronizadas subvertidas. Deste modo podemos compreender como figurações de gênero dentro da ficção científica, e de Survival Ship, poderiam ser negociadas, subvertidas e funcionar como modos de resistência à narrativas padronizadas que dão sentido às relações de poder baseadas nas distinções de gênero. Se compreendermos que os códigos de gênero incluem formas de narrar diferentes corpos, atuações e gestos, podemos entender a adesão a tais figurações ou a opção por outros formatos como atos de suporte ou resistência aos códigos e relações de gênero vigentes.

Joan Scott (1990) observou que o estabelecimento de conceitos normativos, que delimitam a interpretação das figurações e narrativas referentes aos conceitos de masculino e feminino, faz surgir uma posição dominante que se declara como única possível e muitas vezes esta normativa foi interpretada como produto de consenso social. No entanto, houveram conflitos e debates em torno das concepções de masculino e feminino. As narrativas, normas interpretativas e figurações das relações de gênero, assim como os modos de dominação, mudam ao longo da história, são contestados e negociados (SCOTT, 1990). Neste sentido trabalhamos a subversão de narrativas tradicionais da ficção científica, buscando observar o uso de modelos narrativos, geralmente centrados em personagens masculinos, feito por uma autora que deu ao futuro um rosto feminino. Além disso, averiguaremos os modos pelos quais a autora inverte significados e negocia figurações. Para tanto, primeiro, precisamos estabelecer um mapeamento do que eram as narrativas e expectativas padrão acerca das mulheres, como foi feito neste texto, e pensar como a literatura e a escrita da ficção científica podem subverter figurações de gênero conservadoras dos anos 1950.

\section{Narrativas subversivas}

Antes de discutir a subversão das figurações de gênero na ficção científica, é preciso pensar no que faz a ficção quando figura o mundo que chamamos por real. Wolfgang Iser (2017), negando a interpretação da ficção como imitação do real, secundária a este e menos verdadeira, propõe que interpretemos o ficcional como jogo que resulta da transformação dos mundos de referência no texto. Na escrita, elementos selecionados de mundos "reais" e imaginários entram em jogo, interagindo entre si, se rearranjando em relação aos outros elementos e segundo novos padrões determinados pelo autor, criando novas cadeias de significação. Dessa maneira criam-se sequências de referencialidade, ou seja, os elementos do mundo de referência são transformados, 
e dessa mutação emerge algo que não poderia ser deduzido dos mundos de referência. Esse processo é performático; o texto performa cadeias de referencialidades que partem de elementos selecionados, não re-apresenta algo dado.

Para Iser (2017), ao selecionarmos elementos do contexto os retiramos das cadeias semânticas onde estavam inseridos, rearranjamos e ressignificamos estes elementos no texto, os inserimos em um jogo de posições com outros elementos do imaginário, fazemos com que esses elementos se difiram de seu valor e significado original e os colocamos sob o signo do ficcional, do como se. Deste modo os elementos selecionados constituem um mundo outro, que se diferencia do mundo de referência, que se distancia deste. Há um espaçamento entre o sentido criado na literatura e o sentido no mundo de referência, esse espaçamento faz parte do que Iser chamou de diferença operatória entre a mimesis e a referência.

A diferença como movimento de diferir aponta para o mundo ficcional como discernível, não idêntico, possibilitando a separação entre o mundo sob o signo do como se e os mundos atuais. Essa separação torna possível pensar o mundo ficcional como alternativo ou futuro. Neste sentido, Iser dialoga com Nelson Goodman, o qual compreende a ficção como modo de produção de versões de mundo, ou seja, o fictício seria fonte de mundos possíveis, maneira pela qual nos colocamos para além dos limites do nosso mundo atual e imaginamos outros mundos. $\mathrm{O}$ mundo atual estaria cercado de versões de mundos possíveis, elementos destes últimos poderiam ser selecionados para a composição do mundo atual, que está em constante construção. Essa interpretação permite compreender a ficção como intervenção. No ato de leitura, o sujeito pode experienciar diversas versões de mundo possíveis e pode se apropriar de elementos destas para compreender e atuar na sua vida cotidiana, de forma que a ficção é tanto uma forma de acesso à mundos, quanto um elemento compositor desses (ISER, 2017).

Essa leitura da atividade ficcional como performance de mundos possíveis, pelos quais o leitor compreende o mundo que o cerca, permite que pensemos o que seria a subversão na literatura. Ao retirar elementos de suas cadeias semânticas e incluí-los em outras, ao transmutar os significados dos elementos selecionados, o texto subverte o real, no sentido de desmontá-lo, de transformar sua ordem estabelecida; em outros termos, o mundo possível é já uma subversão. O texto pode criar cadeias de significação que invertam a forma das relações sociais que lhe são contemporâneas, imaginando novas formas de interação, ou pode apresentar as mesmas relações com outra conotação, as ironizando. 
A literatura, e principalmente a literatura de ficção científica, apresenta figurações de mundos possíveis, diferentes do atual ao autor ou do passado histórico de sua sociedade. Expressam formas pelas quais autoras imaginaram outros mundos e resistiram a narrativas de seu tempo que definiam papéis femininos. A escrita ficcional traz evidências de formas pelas quais mulheres da década de 1950 encaravam o mundo que as cercava e se posicionavam nele. $\mathrm{O}$ ato de escrita, para uma autora, traz, também, uma questão da apropriação da linguagem por um grupo minoritário de falantes e essa apropriação levanta várias questões delicadas. Dentro do que Showalter chamou de ginocrítica ${ }^{6}$, teorias linguísticas e textuais dedicadas à escrita de mulheres tem se perguntado se escritoras e escritores usam a língua de formas diferentes, se essa diferença pode ser explicada em termos de biologia, socialização ou cultura e se as mulheres podem criar mesmo uma linguagem própria (SHOWALTER, 1994).

No inglês, como em diversas línguas, as categorizações são centradas no homem e moldam nossa percepção e compreensão da realidade. Pesquisadoras, preocupadas com essa centralização e seu impacto, passaram a tematizar qual seria a linguagem adequada para mulheres, pois quando uma mulher escreve ou fala de si mesma, é forçada a falar em uma língua que é, de certo modo, estrangeira e com a qual pode se sentir desconfortável (SHOWALTER, 1994). Para Showalter a questão não é uma possível insuficiência da língua para expressar a consciência das mulheres, mas sim o acesso negado a esse grupo a totalidade da língua, tendo em vista que mulheres foram forçadas ao silêncio, ao eufemismo e ao circunlóquio. Deste modo, a tarefa adequada para a crítica feminista seria concentrar-se no acesso das mulheres à língua, no campo lexical disponível a elas.

A fim de refletir acerca dos usos e apropriações da linguagem pelas mulheres, Showalter parte da ideia de que essas possuem uma cultura comum própria e que um indivíduo do sexo feminino vive dentro de, no mínimo, duas culturas, a cultura feminina ${ }^{7}$ e a cultura masculina

\footnotetext{
6 "Teoria feminista de inspiração anglo-americana que defende que as mulheres têm um processo de leitura e escrita diferentes do homem, por força das diferenças biológicas e das formações culturais da categoria de gênero. Trata-se de uma proposta de abordagem diferente da crítica feminista, porque não prevê a revisão crítica da escrita literária realizado por homens, concentrando-se antes numa escrita exclusivamente feminina. [...] Showalter definiu assim os limites e os objectivos da ginocrítrica: '[gynocriticism] is the study of women as writers, and its subjects are the history, styles, themes, genres, and structures of writing by women; the psychodynamics of female creativity; the trajectory of the individual or collective female career; and the evolution and laws of a female literary tradition." Disponivel em: <https://edtl.fcsh.unl.pt/encyclopedia/ginocritica-gynocriticism/>. Acesso em: 14 ago. 2020.

${ }^{7}$ Showalter (1994) propõe pensarmos a cultura feminina a partir de um ponto de vista centrado nas mulheres, focando nas atividades e objetivos destas, afirmando uma consciência de fraternidade e comunidade. $O$ termo cultura das mulheres, nesse sentido, se refere à comunalidade de valores, instituições, relações e métodos de comunicação, unificando, em certa medida, a experiência desse grupo dentro de determinado recorte.
} 
universalizada - é importante notar que a cultura das mulheres também seria perpassada por recortes raciais, de classe, nacionalidade e etc. Para Edwin Ardener, segundo Showalter, o grupo minoritário, muitas vezes silenciado, e o dominante geram, dentro de suas culturas, crenças ou ideias ordenadoras da realidade social em nível inconsciente, porém o grupo dominante é quem controla as formas ou estruturas nas quais a consciência pode ser articulada, de modo que o grupo silenciado deve mediar suas crenças através de formas permitidas pelas estruturas dominantes (SHOWALTER, 1994).

Elaine Showalter (1994) interpreta, então, a escrita da mulher como um discurso de duas vozes, o qual personifica a herança social, literária e cultural tanto do silenciado quanto do dominante (uma herança que pode ser precária e cheia de lacunas). A escrita feminina não estaria dentro e fora da tradição masculina e feminina, mas sim dentro de ambas simultaneamente. A apropriação da linguagem e sua subversão num texto encontra, portanto, diversos empecilhos: a linguagem utilizada, os moldes e tropos narrativos disponíveis vem de uma cultura dominante, mas formas, estilos, e, no caso, táticas podem vir de uma herança cultural, ou mesmo de uma tradição, feminina. Essa herança de usos da linguagem dentro do gênero da ficção científica é relevante porque a inserção neste código implica leitura e aprendizado de formatos e tropos por meio de trabalhos de outros autores. A produção da ficção científica, e mesmo sua leitura, demanda familiaridade e, por vezes, a participação no fandom. Por outro lado, essa relação com a herança é conflituosa, já que, sendo a ficção científica um gênero voltado para o futuro e que seleciona elementos da tecnologia e ciência, em eterna mutação, para criar produtos culturais, a inovação e o rompimento com o passado do gênero textual acabam sendo demandas as quais uma escritora teria de responder.

Quando pensamos a ficção científica de autoria feminina a partir dessas lentes, é possível perceber a intensa presença de tropos e moldes narrativos pensados a partir do protagonismo de um sujeito masculino que resolve seus problemas pela inteligência, pela bravura e/ou pela violência, e que frequentemente dialoga com o imaginário Western e colonial. Esses tropos e narrativas tradicionais estiveram presentes em trabalhos de autoria feminina, de modo que muitas mulheres escreveram a partir dessa cultura masculina, mas isso não implica que não houve algum tipo de presença da cultura ou tradição feminina nessas obras. No caso de Survival Ship, temos uma narrativa de exploração e colonização de novos territórios, em que uma figura de autoridade militar lidera um grupo o qual deve manter sob controle. Essa narrativa, bastante próxima do 
imaginário de fronteira Western e típica na ficção científica, é, por outro lado, protagonizada por uma mulher, que divide sua autoridade com outras mulheres e está preocupada com a manutenção de sua autoridade nessa posição de poder nova. Deste modo a narrativa apresenta as duas vozes mencionadas por Showalter e seu diálogo é ao menos parcialmente conflituoso de apropriação, subversão e negociação de figurações dentro do tropo tipicamente masculinizado.

No caso de Judith Merril, de modo geral, vemos tropos padrões e modos de narrativa antigos mesclados a cenários e representações que dialogam muito com as figuras femininas da mídia de massa e das revistas. A dona de casa cansada, tentando dar conta das crianças difíceis e pensando em seus eventos sociais, a mãe cautelosa, a filha rebelde e a mulher diligente que parece impecável na sua aparência e trabalho são imagens que costumam aparecer em seus textos. Contudo, esse não é o caso de Survival Ship (1951), em que as mulheres têm pouco, ou mesmo nada, em comum com as mulheres das revistas.

Como observado, a autora se apropria de uma língua da qual possivelmente teve acesso restringido para criar uma narrativa que subverte figurações femininas de seu tempo. Donna Haraway (2009) observa que a letra, a inscrição, tem textualizado corpos femininos, colocado códigos sobre eles e que cabe a história feminista recodificar a comunicação com o objetivo de subvertê-la. Subverter a comunicação, alterá-la, transformá-la, invertê-la e perturbá-la é o que está em questão para a autora. A linguagem é instrumento de luta contra o código único, que traduz todo o significado de forma perfeita e que se impõe sobre os corpos como se fosse fala uníssona.

Haraway advoga pela blasfêmia e pela ironia, formas que trazem significados ruidosos, que jogam com a língua e com as totalidades. A apropriação da linguagem para a resistência contra a definição de papéis e lugares femininos (e mesmo contra a definição e caracterização da mulher), é uma forma de luta dentro do código, contra ele próprio. Ironia, blasfêmia e subversão são formas de transgressão do código, de apropriação da linguagem para criar significados que não convergem com as figuras de gênero prescritas, são maneiras de mover as interpretações ditas corretas dos códigos de gênero (HARAWAY, 2009).

Por fim, essa subversão é feita dentro de outro código: o da ficção científica, um gênero textual voltado para a especulação, que exacerba elementos selecionados referentes à tecnologias e ciências, e que imagina como estes elementos exacerbados impactariam a sociedade e os indivíduos, criando personagens moldados ou que se moldam a tais circunstâncias. As convenções narrativas da SF encorajam escritores a levantar questões sobre as bases biológicas das 
divisões sexuais e os prepara para explorar formulações alternativas de sociedades e psiques individuais. Além disso, a SF busca evocar a sensação de estranhamento na maneira pela qual o leitor olha para seu mundo. Idealmente essa reordenação seria apropriada pelo leitor, que passaria a observar suas próprias experiências com um senso de deslumbramento e questionamento, conhecido na ficção científica como sense of wonder (ATTEBERY, 2002).

A subversão das figurações de gênero na ficção científica significa uma inversão de representações sociais e de imagens femininas alinhadas a essas representações presentes no gênero textual. Essa subversão transforma a figuração, a corrói dentro das medidas do que seria publicável na época. Isso significa que as representações presentes em Survival Ship estão dialogando com as figurações dos papéis de gênero dos anos 1950 e com as representações típicas da ficção científica da época. Cada período teve sua própria maneira de trazer mensagem transgressoras e em cada época escritoras tiveram de ceder a certas normativas para ter seus textos publicados. É difícil, senão impossível, pensar em textos absolutamente rebeldes.

Nos anos 1950 havia a possibilidade de apresentar personagens femininas como mais do que figurantes, mocinhas e fontes de tentação e risco, mas era preciso dialogar com a chamada mística feminina, de modo que essas personagens deveriam ser apresentadas como seres sexuados ou heroínas domésticas. Personagens em cargos militares ou ligados à ciência também eram mães e esposas. Ou seja, para publicar textos que questionavam relações de gênero e figurações comuns da SF, as autoras precisavam utilizar certas convenções narrativas e dominar os códigos da SF e de gênero (YASZEK, 2008).

\section{Survival Ship}

Quinhentas mil pessoas foram assistir a decolagem da nave Survival, enquanto cem milhões assistiram o evento da televisão. Na filmagem, narra Merril, via-se uma mão de Cap. Melnick acenando uma despedida dramática enquanto a outra mão abaixava a alavanca que disparava a nave para fora da órbita espacial do satélite de onde partiam em direção ao espaço intergaláctico. O destino da nave era a constelação de Sírius, onde os tripulantes buscariam por um planeta capaz de sustentar vida humana para o estabelecimento de uma colônia. O tempo mínimo da viagem seria de 30 anos (MERRIL, 1951). 
A escritora conta que a decolagem pesadamente coberta pela imprensa não dava conta de dois detalhes: a identidade dos tripulantes e porque essas identidades estavam em segredo. Era, também, de conhecimento público que milhares de engenheiros recém-formados se inscreveram para a missão. Era necessário ter menos de 25 anos, ser solteiro, formado em engenharia e estar fisicamente apto. Os escolhidos eram de ambos os sexos (24 indivíduos), pois era necessário que estes procriassem para que houvesse uma segunda geração de astronautas que pudesse retornar à Terra caso um grupo tivesse de ficar em algum planeta habitável (MERRIL, 1951).

Assim como o público terrestre que assistia a cobertura de imprensa, os leitores também desconhecem as identidades dos personagens. Nem gênero e nem nomes são informados no início do texto, apenas ranking e sobrenome de certos personagens, como Cap. Melnick e Tte. Johnson. A narração foca nas ações precisas, competentes e focadas de Melnick:

\begin{abstract}
Ajustando o cinto da poltrona com competência veloz e hábil, Cap. Melnick assistiu atentamente ao movimento dos ponteiros do cronômetro de decolagem, consciente, ao mesmo tempo, que a luz verde começava a brilhar no outro extremo da placa de comando. $\mathrm{O}$ indicador atingiu a primeira marca vermelha: 'O show acabou, pessoal. Estamos safos!' o microfone embutido no descanso de queixo carregou sua voz pela nave. 'Todos os postos, reportar.' (MERRIL, 1951: p.60, tradução nossa) ${ }^{8}$
\end{abstract}

A narrativa de Merril não indica gênero, mas é muito próxima às clássicas formas de apresentar um Capitão. Movimentos ágeis e precisos, atenção focada, pensamento racional e estratégico, voz imperativa. Facilmente essas características podem ser encontradas em protagonistas de SF anteriores e mesmo nos capitães de ficções posteriores, como Kirk ou Picard. Ainda, a imagem expressa por Merril não figura a forma física da protagonista, seu olhar, aspecto ou modos. De modo que a autora nega, já no princípio do texto, a figuração típica de uma personagem feminina, para apresentar um indivíduo cujos atos importam mais do que a aparência. Nega-se a primazia da beleza e evidencia-se a eficiência, dois elementos das narrativas típicas de gênero já estão sendo subvertidos nos primeiros momentos do texto.

A seguir, Cap. Melnick apresenta suas preocupações com a manutenção da autoridade e hierarquia. Após o sono induzido Melnick deveria acordar antes dos oficiais e antes do restante da tripulação, pois se um de seus homens apresentasse maior habilidade recuperativa isso poderia

\footnotetext{
8 "Securing the couch straps with the swift competence of habit, the captain intently watched the sweep of the big second hand around the take-off timer, aware at the same time that green lights were beginning to glow at the other end of the board. The indicator reached the first red mark. 'The show's over, everybody. We're in business!' The mike built into the chin rest carried the captain's taut voice all over the ship. 'Report, all stations!' (MERRIL, 1951: p.60)
} 
implicar numa contestação de sua autoridade. A manutenção da hierarquia era essencial, pois a viagem tomaria cerca de 30 anos, tempo em que a tripulação viveria dentro de "dominações artificiais" (MERRIL, 1951: p.62, tradução nossa) ${ }^{9}$ que desafiavam as condições normais terráqueas.

Os conflitos na hierarquia da nave advêm da inortodoxia nas relações de gênero. Ao colocar mulheres nos cargos de comando da nave, a missão inverteu uma estrutura de comando tradicional da sociedade patriarcal e o fez em uma estrutura especialmente masculina: a militar. Ainda que levando em consideração que as missões espaciais contaram com participação feminina em terra, a figura do astronauta era claramente masculina no período de escrita do conto, de modo que pensar mulheres nessa posição envolvia levar em consideração os problemas que estas enfrentariam e como os solucionariam. O texto dá à Capitã Melnick uma imagem pesada, direta, quase bruta, assumindo atributos caracterizados como masculinos no imaginário dos anos 1950. Essa troca de características permite a atuação dessa personagem no cargo que ocupa, ou seja, essa caracterização pode ter a função de tornar o texto mais cabível a um leitor da época, assim como pode significar um questionamento da autora acerca de um modo de inserção das mulheres no mercado de trabalho da época: mulheres que adentravam o mercado tinham de se portar como homens, se adaptando a suas roupas, gestuais e hierarquias. Esses moldes de inserção foram questionados pela segunda onda do feminismo e podem ter sido, também, questionados pela autora. Por outro lado, essa caracterização também pode significar uma negociação com os códigos de gênero vigentes, como já dito, e pode significar uma busca de um maior leque de comportamentos entendidos como aceitáveis quando praticados por um corpo feminino - uma subversão que busca desafiar ou moldar o código vigente.

Acerca da mulher como astronauta, em 1951 ainda não havia ocorrido nenhum esforço efetivo para enviar mulheres ao espaço nos Estados Unidos. No entanto, havia uma necessidade de atuação feminina como força de trabalho para a corrida espacial. Para incentivar mulheres a atuarem como cientistas e engenheiras, o governo americano teve de ir de encontro às propagandas de incentivo à domesticidade e aprovar, em 1958, o Ato Nacional de Defesa da Educação, que garantia bolsas para estudantes de matemática, ciência, línguas estrangeiras e outras áreas ligadas à defesa nacional, independentemente de raça, classe ou gênero. Ainda, em 1959, a National Aeronautics and Space Administration (NASA) iniciou um programa cujo

\footnotetext{
9 “artificial dominance” (MERRIL, 1951: p.62)
} 
objetivo era o recrutamento de treze das melhores aviadoras do país para treiná-las como astronautas. Contudo, em 1962 esse programa foi oficialmente finalizado, logo após o envio soviético do primeiro homem ao espaço (YASZEK, 2008).

Para Yaszek (2008), independemente da sua vida curta, o projeto já mostrava como uma nova tecnocultura exigia transformações nos ideais de feminilidade. Essa demanda está presente nas novas formas de relações de gênero e sexuais presentes em Survival Ship, em que, devido a novas demandas científicas, estruturas tradicionais são contestadas. Essa contestação é evidenciada no discurso da Cap. Melnick no primeiro jantar da viagem. A capitã arranjou os horários de trabalho de modo que pudesse, primeiro, falar com as tripulantes antes dos homens voltarem de suas funções. No refeitório, essas esperavam com seus "rostos bronzeados e corpos musculosos" (MERRIL, 1951: p.65, tradução nossa) ${ }^{10}$. Melnick explicou que a nave se chamava Survival e todas sabiam o motivo do nome: 1) $O$ sucesso da missão poderia garantir a sobrevivência da espécie humana; 2) os arranjos feitos para a sobrevivência da tripulação, composta por indivíduos de ambos os sexos com um propósito de procriação; mas o segredo sobre a tripulação mista era sua proporção. Para garantir a tripulação necessária para ida a Sirius e retorno, a população precisava ser composta por vinte mulheres e quatro homens. Deste modo a proposta seria de que cada um destes homens se reproduzisse com cinco mulheres diferentes e todas as crianças fossem criadas coletivamente (MERRIL, 1951).

A autora conta que essa divisão estava em completo desacordo com princípios éticos estabelecidos na paz pós-4a Guerra Mundial, mas os organizadores da viagem conseguiram entrar em acordo com as autoridades e aprovar a divisão. $\mathrm{O}$ projeto ganhou consentimento apenas porque os mais altos membros do clero "entenderam que as condições do nosso pequeno universo eram diferentes daquelas da Terra de todas as maneiras - e que a divisão proposta era necessária para a sobrevivência" (MERRIL, 1951: p.66, grifo da autora, tradução nossa) ${ }^{11}$. Após o consentimento político e religioso, a viagem foi organizada com a nova estrutura familiar em segredo.

A organização em si é simples: originalmente encontros aleatórios seriam planeados para que todos conhecessem seus possíveis parceiros (aparentemente dentro de limites heterossexuais e com encontros de apenas duas pessoas), cada indivíduo faz suas seleções, uma vez que as seleções

\footnotetext{
10 "bronzed faces and trimly muscled bodies" (MERRIL, 1951: p.65)

11 "understood that the conditions of our small universe were in every way different from those on Earth-and that the division proposed was necessary for survival." (MERRIL, 1951: p.66)
} 
sejam recíprocas, começaria a se formar um grupo de seis pessoas, ao qual seriam designados aposentos permanentes, e, por fim, cronogramas de maternidade seriam organizados (o que pode pressupor o uso de algum tipo de contraceptivo). Uma vez que o grupo esteja organizado, as práticas sexuais em si ficam em aberto no texto, só é dito que: "Eu penso que será possível, de fato necessário, permitir maior autonomia dentro destes grupos” (MERRIL, 1951: p.67, tradução nossa) $)^{12}$.

Por mais que organizada de outra maneira, a estrutura familiar e sexual continua tendo cunho de obrigatoriedade no texto, a heterossexualidade continua sendo ao menos parcialmente compulsória (bi e panssexualidade parecem possíveis nesse quadro), e as capacidades reprodutivas dos indivíduos continuam sendo de interesse público:

A sobrevivência da raça é nosso dever ético como homens e mulheres [...] O que nós estamos fazendo, nosso modo de vida agora, foi aprovado pelas autoridades, devemos lembrar-nos disso. Na Terra, a sobrevivência da raça é melhor garantida pela fortificação dos laços familiares e não era sábio colocar esses laços em perigo, deixando o público geral saber deste sistema - heterodoxo - em jogo aqui. [...] O conhecimento de que existem vinte de um sexo na nave e apenas quatro de outro - a ideia de que as crianças serão criadas coletivamente e fora de estruturas familiares normais - eu não preciso dizer a vocês quão desastroso teria sido. (MERRIL, 1951: p.67, tradução nossa) ${ }^{13}$

A sexualidade perpassa relações sociais diversas, suas funções reprodutivas são acompanhadas, normatizadas e discutidas por diferentes esferas que não as reprimem nem silenciam, mas intensificam corpos e sua descendência (FOUCUALT, 1998). A sexualidade e reprodução são deveres perante a raça humana como um todo, elas redefinem estruturas sociais do ambiente extraterrestre e são perpassadas, validadas, debatidas e organizadas por figuras de autoridade militar, política e religiosa. A sexualidade na nave é falante e tem funções de maximização do bem-estar da raça humana e aspecto de dever moral.

No que tange a forma familiar, o que ela traz de inovador para as mulheres em específico é a necessidade de que elas estejam nas posições de comando e responsabilidade - o motivo dessa mudança não é esclarecido pela autora, a qual informa apenas que é pelo bem-estar da nova forma familiar. Desse modo, Merril justifica a mudança nas performances de gênero esperadas através das necessidades reprodutivas de um grupo cujo dever máximo é a preservação da espécie

\footnotetext{
12 "I think it will be possible, in fact necessary, to allow a greater amount of autonomy within those groups." (MERRIL, 1951: p.67).

13 "On Earth, survival of the race is best served by the increasing strength of family ties. It was not thought wise to endanger those ties by letting the general public become aware of our-unorthodox-system here on board. [...] "The knowledge that there are twenty of one sex on board, and only four of the other-that children will be born outside of normal family groups, and raised jointly-I need not tell you how disastrous that would have been." (MERRIL, 1951: p.67).
} 
humana. A autora, sob o signo do como se, dialoga com expectativas heteronormativas familiares e as utiliza para apoiar mudanças nas relações de poder entre gêneros.

Contudo, não bastou figurar mulheres no poder, mas era necessário discutir como elas pretendiam mantê-lo, pois, para Merril e para o leitor assumido, essa mudança desafiava certas expectativas sociais, gerando um risco de desordem. Neste sentido Cap. Melnick expõe que:

\begin{abstract}
Nós não somos apenas mais numerosas que eles, mas somos mais fortes e, nos nossos cargos, mais afortunadas [o único personagem masculino apresentado está no cargo de jardineiro]. Nós devemos nos acostumar ao fato de que eles são nossa responsabilidade. É porque somos mais duras, mais vividas, menos suscetiveis a doenças e dores, mais aptas a aguentar, mentalmente, dificuldades da monotonia, que estamos onde estamos [...]. (MERRIL, 1951: p.67, grifo nosso, tradução nossa $)^{14}$
\end{abstract}

Essa figuração das personagens como mais fortes, duras e aptas pode funcionar dentro do texto como uma justificativa da posição ocupada pelas astronautas na hierarquia da espaçonave. Essa figuração inverte as expectativas sociais do período e coloca mulheres inclusive como mais experientes que homens. Ao mesmo tempo, essa demanda também dialoga com o equilíbrio e a performance perfeita demandada das mulheres nos anos de 1950, época na qual poucas mulheres conseguiam cumprir essas expectativas de força interna coberta por uma suavidade externa, resultando em múltiplos quadros de adoecimento mental (SHOWALTER, 2009). De modo geral, essa força e habilidade de dureza aparecem nos textos de Merril de maneira celebrativa, a resistência e capacidade de encarar situações desafiadoras das personagens são parte de sua caracterização como heroínas. Algo que dialoga com as propostas da ficção científica de 1950, período de atuação de Joseph Campbell como escritor e editor da Astounding Science Fiction, em que as figuras de super-homens e indivíduos de força e habilidade exemplar borbulhavam no imaginário da SF. O código de gênero parece subvertido enquanto que o código da ficção científica parece mantido, mas negociado para dar forma à subversão de gênero.

Neste excerto, não só as mulheres não são apresentadas como frágeis, infantilizadas e ingênuas, mas são caracterizadas como resistentes, experientes e treinadas, capacitadas para o comando e para sustentar possíveis resistências a suas autoridades. O trecho em itálico se refere à passagem em que concepções e figurações normalizadas do feminino, tanto por revistas quanto pela ficção científica, são subvertidas. Nos anos 1950 havia certa quantidade de protagonistas

\footnotetext{
14 "We are not only more numerous than they, but we are stronger and, in our social placement here, more fortunate. We must become accustomed to the fact that they are our responsibility. It is because we are hardier, longer-lived, less susceptible to pain and illness, better able to withstand, mentally, the difficulties of a life of monotony, that we are placed as we are [...]." (MERRIL, 1951: p.67)
} 
mulheres, mas a construção destas como responsáveis por uma nave não era algo usual, e o mesmo pode ser dito da descrição de personagens femininas como duras, vividas, fortes e musculosas. Merril também associa atratividade à força física - "rostos bronzeados e corpos musculosos".

Esse tipo de figuração é possível através de artimanhas narrativas em que a realidade é suspensa e, sob o signo do como se, é proposto ao leitor que imagine quais seriam as demandas de uma viagem espacial de longo prazo e da possível colonização de outro planeta. Além disso, o destino da raça humana como um todo está em risco caso a missão não atinja sucesso, ou seja, a autora utiliza de certas normativas morais para se desvencilhar de outras e criar um universo onde mulheres poderiam estar em posições de comando - caso sejam fortes e estejam de acordo com expectativas reprodutivas heteronormativas. A subversão seria, neste sentido, diretamente ligada a um ato de negociação, que, como explicou Justine Larbalestier(1996), é comum à ficção científica dos pulps. Escritoras traziam outras imagens para as personagens femininas, criavam protagonistas e buscavam narrar histórias partindo de suas perspectivas, mas também aceitavam, até certo ponto, a figuração da mulher no lugar de dona-de-casa, esposa e mãe. Resistência à imposição dessa forma de performar o feminino e conivência com essa representação se misturam nos textos e participações no campo da SF.

Outra estratégia usada por Merril que merece menção é a omissão do gênero dos personagens; é só no final da narrativa que a autora revela o gênero e qual o mistério por trás das identidades das personagens. Os nomes escolhidos são neutros e, quando a escritora se refere aos homens da tripulação, ela utiliza a concepção de "homem(ns)" ("man" ou "men") como categoria universal para dar pistas no texto sem revelar o enredo ${ }^{15}$. Por fim, a autora apresenta a Cap. Melnick sem utilizar nenhuma forma narrativa comumente relacionada a uma mulher, como descrição física ou confusão mental. Melnik age de maneira racional, autoritária, direta e analítica do começo ao fim do texto, sua aparência nunca é descrita. $O$ resultado dessa figuração é a criação da expectativa no leitor, acostumado com esse tipo de narrativa, de que Melnick seja um homem. Merril subverte essa expectativa ao mesmo tempo que a denuncia.

\section{Considerações finais}

\footnotetext{
${ }^{15}$ Algumas pesquisadoras interpretam que o texto foi um experimento falho na omissão de gênero, o que implicaria que o que esse trabalho interpretou como pistas poderia ser compreendido como erros da autora.
} 
Após a 2a Guerra Mundial, o discurso oficial norte-americano pedia o retorno das mulheres aos lares, onde era esperado que essas cuidassem de seus maridos, vigiassem seus filhos e consumissem. Esse discurso teve impacto, mas não eliminou a atuação da mulher no mercado de trabalho e na escrita de ficção científica. Como escritoras, mulheres adaptaram os tropos e elementos característicos da ficção científica para acoplar protagonistas mulheres. Ainda que podendo trazer heroínas nos seus textos, as autoras dos anos 1950 tinham certas expectativas pesando sobre si no campo, suas heroínas deveriam parecer cabíveis e as autoras deveriam ser, também, memoráveis enquanto mães e esposas ${ }^{16}$. Contudo, dentro dessas expectativas, autoras conseguiram questionar relações de gênero, sexuais e figurações típicas de mulheres feitas no campo e fora dele, por meio de estratégias de subversão que se apropriaram de tropos e alteraram seus significados ou padrões de funcionamento.

A literatura, ao selecionar elementos do mundo que lhe é atual e colocá-los em jogo com elementos ficcionais, retira esses elementos de suas cadeias semânticas, os insere em novas cadeias e, no texto, transforma o mundo de referência em mundo performando, mundo possível. Neste como se, relações sociais e concepções de feminino e masculino do mundo de referência, seus símbolos e narrativas associadas às categorias de homem e mulher, podem ser alterados em sua forma e significado. É o caso de Survival Ship, que narrou a história da decolagem de uma nave gerida por mulheres descritas como fortes, resistentes e experientes. Essa mudança na forma de figuração feminina se faz compreensível pelo novo cenário onde se dá: o ambiente de uma nave espacial. Ou seja, o texto negocia uma figuração e apresenta uma imagem feminina alternativa, mas a justifica. Além disso, as capacidades reprodutivas destas mulheres continuam sendo definidoras de seus papéis sociais, já que toda a estrutura em que o pessoal da nave foi colocado é pensada para maximizar a reprodução.

Discutir essa negociação e as formas em que se deu é, também, discutir a maneira pela qual escritoras deram à literatura de ficção científica um rosto feminino, criando e disputando espaços para as mulheres no futuro. Em 1981, Elaine Showalter afirmou que a crítica feminista poderia pensar os textos escritos por mulheres como indícios de como essas vivem e têm vivido,

\footnotetext{
${ }^{16}$ Na edição de janeiro de 1951 da revista Worlds Beyond, Judith Merril foi descrita como uma "efficient and determined young woman who has made an enviable place for herself in the science-fantasy field from a standing star just five years ago. Her Bantam Books anthology, Shot in The Dark sold half a million copies; her novel Shadow on the hearth (Doubleday, 1950), has been chosen for early distribution by the Fictional Book Club[.... Miss Merril (whose legal name is Mrs. Frederik Pohl) recently became the mother of a six-pound, fourteen-ounce baby girl" (1951: contra-capa)
} 
como imaginam e como a linguagem as aprisiona e liberta, como o ato de nomear tem sido uma prerrogativa masculina e como podemos começar a nomear (SHOWALTER, 1991). É em uma chave como essa que este trabalho buscou compreender a atuação de Judith Merril e seu texto. Quando Merril pública, assina como mulher e fala de mulheres, ela retoma a habilidade de nomear.

\section{Fonte}

MERRIL, Judith. Survival Ship. In: KNIGHT, Damon (ed.). Worlds Beyond. New York: Hillman Periodicals, Inc., v. 01, n. 02, janeiro de 1951

\section{Referências}

ATTEBERY, Brian. Decoding Gender in Science Fiction. New York: Routledge, 2002.

BUTLER, Judith P. Problemas de gênero : feminismo e subversão da identidade. Rio de Janeiro: Civilização Brasileira, 2003.

Changes in women's labor force participation in the 20th century. Secretaria de Estatísticas. História da sexualidade: a vontade de saber. Rio de Janeiro: Paz e Terra, 2014.

FRIEDAN, Betty. A mística feminina. Petrópolis, RJ: Editora vozes, 1971.

HARAWAY, Donna J. Manifesto ciborgue: ciência, tecnologia e feminismo socialista no final do século XX. Belo Horizonte: Autêntica, 2009, p. 35-89.

ISER, Wolfgang. O fictício e o imaginário: Perspectivas de uma antropologia literária. Rio de Janeiro: Ed. UERJ, 2017.

LARBALESTIER, Justine. The battle of sexes on science fiction : from de pulps to the James Tiptree, Jr. Memorial Award. 394 f. Tese (Doutorado em Filosofia) - Department of English. University of Sydney. 1996. Disponível em: <https://ses.library.usyd.edu.au/handle/2123/401>. Acesso em: 12 jul. 2020.

LAMONT, Victoria; NEWELL, Diane. Judith Merril: A Critical Study. Jefferson, North Carolina: 2012.

LEFAUCHEUR, Nadine. Maternidade, Família, Estado. In: DUBY, George; PERROT, Michelle (org.). A história das mulheres no Ocidente: o século XX. São Paulo: Ebradil, 1991.

MARTIN, Matthew. Women in Space: Feminist Pulp Science Fiction From 1927-1948. 89 f. Dissertação (Mestrado em Artes) -City College. City University of New York. 2014. Disponível em: 
<https://academicworks.cuny.edu/cgi/viewcontent.cgi?referer=https://scholar.google.com.br/ $\&$ httpsredir=1\&article=1230\& context=cc_etds_theses $>$. Acesso em: 11 jul. 2020.

SCOTT, Joan. Gênero uma categoria útil. Educação e Realidade. Porto Alegre, v. 05, n. 02, p. 71 99, jul-dez, $1990 . \quad$ Disponível em: <https://seer.ufrgs.br/index.php/educacaoerealidade/article/view/71721>. Acesso em 13 jul. 2020.

SHOWALTER, Elaine. A crítica feminista no território selvagem. In: HOLLANDA, Heloisa Buarque de. Tendências e impasses, feminismo como crítica cultural. Rio de Janeiro: Rocco, 1994.

A jury of her peers: American women writers from Anne Bradstreet to Annie Proulx. New York: Alfred A. Knopf, 2009.

[s.n.], 1999.

A literature of their own: British woman novelist from Bronte to Lessing. [s.1.]:

YASZEK, Lisa. Galactic suburbia: recovering women's science fiction. Ohio: The Ohio State University Press, 2008.

\section{Sobre a autora:}

Janis Caroline Boiko da Rosa: Graduada em História pela PUC-PR, mestra pela UFPR. Atualmente doutoranda no departamento de História da UFPR. Bolsista CAPES.

Artigo recebido para publicação em: 13 de abril de 2021.

Artigo aprovado para publicação em: 03 de dezembro de 2021.

\section{Como citar:}

ROSA, Janis Caroline Boiko da. Figurações femininas subvertidas no conto Survival Ship (1951) de Judith Merril: ficção científica e gênero em negociação. Revista Transversos. Dossiê: O futuro do passado: Desafios para o Ensino da História nas escolas numa perspectiva global. Rio de Janeiro, $\mathrm{n}^{\circ}$. 23, 2021. pp. 361-382. Disponível em: <https://www.epublicacoes.uerj.br/index.php/transversos/article/view/59121>. ISSN 2179-7528. DOI: $10.12957 /$ transversos.2021.59121

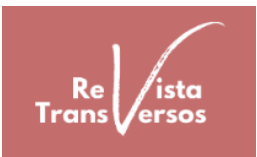

